\title{
A new integrated group decision making framework with linguistic interval fuzzy preference relations
}

\author{
Gülçin Büyüközkan ${ }^{1}$ Sezin Güleryüz ${ }^{1,2}$ \\ ${ }^{1}$ Galatasaray University, Industrial Engineering Department, \\ 34357, Ortaköy-Istanbul, Turkey \\ ${ }^{2}$ Bartın University, Industrial Engineering Department, \\ 74100, Bartın-Turkey
}

\begin{abstract}
The high complexity of socio-economic environments often makes it difficult for a single decision maker (DM) to consider all important aspects of decision problems. Therefore, a group decision making (GDM) process is often preferred by organizations. Moreover, during the decision process, DMs may have difficulties in the prioritization of alternatives. Linguistic interval fuzzy preference relation is a strong tool which can deal with uncertainty in case of subjective and vague information. For this reason, this paper develops a new GDM approach based on integrated linguistic interval fuzzy preference relation and analytic network process. To demonstrate the applicability of the proposed approach, an illustrative example is presented.

Keywords: Group decision making, Linguistic interval fuzzy preference, Analytic network process, Consensus model.
\end{abstract}

\section{Introduction}

As the complexity of the socio-economic environment is much increased today, many organizations make use of a group of decision makers (DMs - experts) instead of a single DM to accomplish the given tasks successfully [1-3].The group decision making (GDM) consists of multiple individuals interacting to reach a decision [4]. Each DM may have unique motivations or goals and may approach the decision process from a different angle, but have a common interest in reaching eventual agreement on selecting the "best" option(s). To do this, experts have to express their preferences by means of a set of evaluations over a set of alternatives. Recently, linguistic preference relations used by DMs to express their linguistic preferences when comparing decision alternatives have been investigated in the literature [5-10].

Moreover, at modeling of real life situations, DMs may not be able to discriminate explicitly the degree to which an alternative is better than another or may not estimate his/her preference with only one label. In such cases, linguistic interval fuzzy preference relations is useful for adequately modeling the uncertainty and imprecision in decision making processes [11].

While dealing with linguistic interval fuzzy preference relations of DMs, the solution procedure should also consider the dependence and interactions among decision criteria. The increasing complexity and uncertainty of the socio-economic environment makes it less possible to assume all criteria as independent. Hence, this work proposes a new integrated GDM approach based on the analytic network process (ANP) [12] method with linguistic interval fuzzy preference relations [11]. As linguistic interval fuzzy preference relations are not widespread currently, the main contribution of this paper is the integration of linguistic interval fuzzy preferences into the ANP model.

The paper is organized as follows. Section 2 presents the literature survey briefly. Section 3 describes the methodology adopted in the paper and characterizes the novel computational procedure. Section 4 includes an implementation of the proposed evaluation framework through an illustrative example. Section 5 concludes the paper.

\section{Literature Survey}

In decision making problems preference relation is the most well-known and widely used representation of information. It is an advantageous tool to model decision processes, when there is a necessity to combine experts' preferences into a new form of group preferences [13-15].The linguistic information can be defined as a variable whose values have the form of words, phrases or sentences rather than numbers in a natural language [16-17]. Moreover, linguistic variables help to model problems in a qualitative ways which is typical in human communication for representing qualitative concepts such as "importance" or "significance" [16].

In this view, fuzzy set theory is assessed in complex situations which include imprecise information in DMs assessments. In other words, experts could have some difficulties for estimating their preference degrees with exact numerical values. Under these circumstances, fuzzy linguistic approach is used in order to capture all data, manage linguistic information and provide better solution [18-19].

In the GDM process, aggregating each DM's decision information is the key [1,6]. Literature on linguistic fuzzy preference relations mainly focus on operators in aggregation processes. Since the ordered weighted averaging (OWA) operator was first generated by Yager [21] in 1988, many aggregation operators such as the linguistic weighted ordered weighted averaging (LOWA) operator [5, 22] and linguistic ordered weighted geometric averaging (LOWGA) operator [8] have been developed. 
On the other hand, interval fuzzy preference relations are useful tools to describe experts' preferences in GDM under uncertainty. The concept of interval fuzzy preference relation was first introduced by $\mathrm{Xu}$ [23], based on interval fuzzy preference relation. In this study a priority method was given to determine the weights of objects, and a possibility degree formula is used to rank and select the given objects. In addition to this, some authors investigated similarity measures, aggregation and priority methods of interval fuzzy preference relations. For example, $\mathrm{Xu}$ [24] defined the concept of compatibility degree of two interval fuzzy preference relations, and showed the compatibility relationship among individual interval fuzzy preference relations and collective interval fuzzy preference relation. Herrera et al. [25] developed an aggregation process for combining interval fuzzy preference relations.

In GDM problems, DMs' opinions may differ substantially. Therefore, it is necessary to develop a consensus process in an attempt to obtain a solution of consensus [6]. Classically, consensus is defined as the full and unanimous agreement of all the experts (DMs') regarding all the possible alternatives. Recently, Tapia Garcia et al. [11] propose a new consensus model for GDM problems with linguistic interval fuzzy preference relations. They use two kinds of consensus measures to guide the consensus reaching processes, which are consensus degrees (to evaluate the agreement of all the experts) and proximity degrees (to evaluate the agreement between the experts' individual preferences and the group preference). Besides, the consensus process discusses how to obtain the maximum degree of consensus or agreement among a set of experts. Therefore, this process is necessary to obtain a final solution with a certain level of agreement among experts [26]. Then, both measures on the three levels of representation of linguistic interval fuzzy preference relations are computed, which are: level of pair, level of alternative and level of relation.

\begin{tabular}{|c|c|c|c|c|c|}
\hline Year & Ref. & Methodology & Operator & Area & Type \\
\hline 2004 & [27] & Linguistic interval & FN- IOWA & - & $\begin{array}{l}\text { Illustrative } \\
\text { Example }\end{array}$ \\
\hline 2008 & [28] & Linguistic interval & WC- OWA & - & $\begin{array}{l}\text { Illustrative } \\
\text { Example }\end{array}$ \\
\hline 2008 & [29] & $\begin{array}{l}\text { Interval fuzzy pref. } \\
\text { relation. }\end{array}$ & - & - & $\begin{array}{l}\text { Illustrative } \\
\text { Example }\end{array}$ \\
\hline 2008 & [30] & $\begin{array}{l}\text { Interval fuzzy pref. } \\
\text { relation }\end{array}$ & - & - & $\begin{array}{l}\text { Illustrative } \\
\text { Example }\end{array}$ \\
\hline 2011 & [31] & $\begin{array}{c}\text { Uncertain linguistic } \\
\text { variables, } \\
\text { interval probability }\end{array}$ & - & Investment & $\begin{array}{l}\text { Illustrative } \\
\text { Example }\end{array}$ \\
\hline 2011 & [32] & $\begin{array}{c}\text { Interval fuzzy pref., } \\
\text { Quadratic prog. } \\
\text { model }\end{array}$ & - & Military & $\begin{array}{l}\text { Illustrative } \\
\text { Example }\end{array}$ \\
\hline 2012 & [33] & $\begin{array}{l}\text { Fuzzy linguistic with } \\
\text { 2-tuples, consensus }\end{array}$ & - & - & $\begin{array}{c}\text { Illustrative } \\
\text { Example }\end{array}$ \\
\hline 2012 & [11] & $\begin{array}{c}\text { Linguistic } \\
\text { interval,consensus }\end{array}$ & LOWA & - & $\begin{array}{c}\text { Illustrative } \\
\text { Example } \\
\end{array}$ \\
\hline 2013 & [34] & $\begin{array}{c}\text { Interval intuitionistic } \\
\text { uncertain linguistic } \\
\text { variables }\end{array}$ & $\begin{array}{l}\text { IVIULWGA } \\
\text { IVIULOWG }\end{array}$ & $\begin{array}{c}\text { Developing } \\
\text { rural area }\end{array}$ & $\begin{array}{c}\text { Illustrative } \\
\text { Example }\end{array}$ \\
\hline 2013 & [35] & $\begin{array}{l}\text { 2-tuple linguistic } \\
\text { information }\end{array}$ & $\begin{array}{l}\text { IVTWG,IVTOWG } \\
\text { GIVTWA } \\
\text { GIVTOWA }\end{array}$ & - & $\begin{array}{l}\text { Illustrative } \\
\text { Example }\end{array}$ \\
\hline
\end{tabular}

Table 1. Several studies make use of GDM with linguistic interval fuzzy preferences
Then, an automatic feedback mechanism is applied to guide experts in the consensus reaching process and substitute their considerations in the DM process [26].

Several authors have previously studied the GDM methodology with linguistic interval fuzzy preferences. Table 1 lists a sample of those studies.

\section{Computational procedure of the proposed approach}

The general view of the proposed GDM approach which is based on integrated linguistic interval fuzzy preference relation and analytic network process is given in Figure 1.

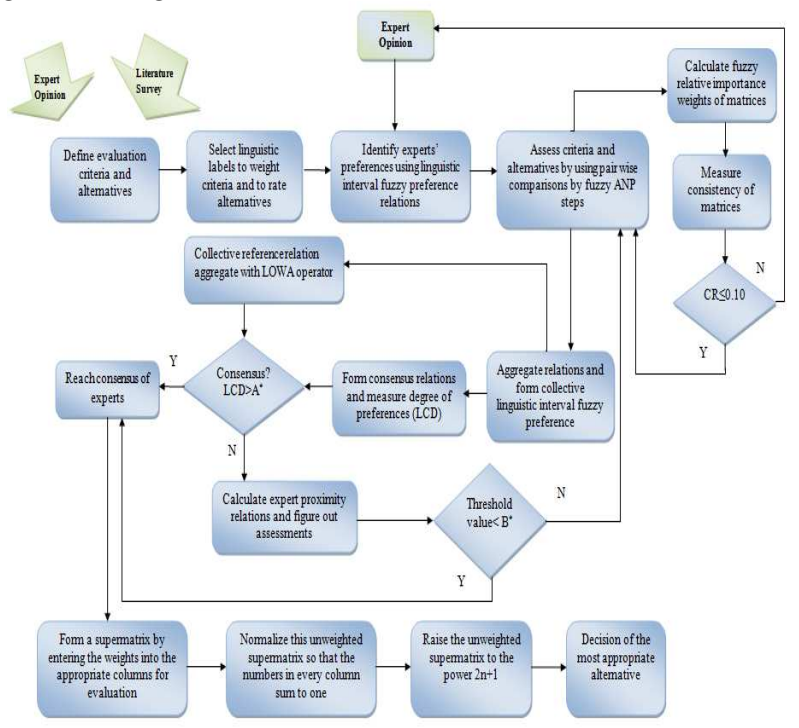

Fig 1. A general view of the proposed integrated methodology $\left(A^{*}\right.$ and $B^{*}$ are threshold values)

The computational steps of the proposed approach are as follows:

Step 1: Construct a committee of experts (DMs), determine the alternatives and develop the network structure for evaluation.

Step 2: Design and select a comparison scale to weight criteria set and to rate alternatives.

Trapezoidal fuzzy intervals are often used in practice. The reason of their popularity is that trapezoidal membership functions are better than triangular membership functions with respect to representing the problem more realistically [36]. Moreover, according to Herrera and Herrera-Viedma [26], [37] it is considered that linear trapezoidal membership functions are good enough to capture the vagueness of these linguistic assessments [37-39]. Table 2 gives the nine linguistic label set with their respective associated semantics to express the preferences.

Step 3: Construct and evaluate the pair-wise comparison matrices with linguistic interval fuzzy preference relations. 


\begin{tabular}{|l|c|c|}
\hline $\mathrm{s}_{8}=\mathrm{C}$ & Certain & $(1.00,1.00,0.00,0.00)$ \\
$\mathrm{s}_{7}=\mathrm{EL}$ & Extremely likely & $(0.98,0.99,0.05,0.01)$ \\
$\mathrm{s}_{6}=\mathrm{ML}$ & Most likely & $(0.78,0.92,0.06,0.05)$ \\
$\mathrm{s}_{5}=\mathrm{MC}$ & Meaningful chance & $(0.63,0.80,0.05,0.06)$ \\
$\mathrm{s}_{4}=\mathrm{IM}$ & It may & $(0.41,0.58,0.09,0.07)$ \\
$\mathrm{s}_{3}=\mathrm{SC}$ & Small chance & $(0.22,0.36,0.05,0.06)$ \\
$\mathrm{s}_{2}=\mathrm{VLC}$ & Very low chance & $(0.10,0.18,0.06,0.05)$ \\
$\mathrm{s}_{1}=\mathrm{EU}$ & Extremely unlikely & $(0.01,0.02,0.01,0.05)$ \\
$\mathrm{s}_{0}=\mathrm{I}$ & Impossible & $(0.00,0.00,0.00,0.00)$ \\
\hline
\end{tabular}

Table 2. Corresponding linguistic terms for evaluation [10]

Step 4: Aggregate of linguistic interval fuzzy preference relations [11].

The Linguistic Ordered Weighted Averaging (LOWA) is used as an operator in order to aggregate nonweighted ordinal linguistic information [11],[40]. Suppose that $\left\{\mathrm{a}_{1}, \ldots, \mathrm{a}_{\mathrm{m}}\right\}$ be a set of labels to be aggregated, then the LOWA operator, $\phi$, is defined as $\phi\left(\mathrm{a}_{1}, . . \mathrm{a}_{2}\right)=\mathrm{W} . \mathrm{B}^{\mathrm{T}}=\mathrm{C}^{\mathrm{m}}\left\{\mathbf{W}_{\mathbf{k}}, \mathbf{b}_{\mathbf{k}}, \mathbf{k}=\mathbf{1}, \ldots \mathbf{m}\right\}$

$=\mathrm{w}_{1} \odot \mathrm{b}_{1} \oplus\left(1-\mathrm{w}_{1}\right) \odot \mathrm{C}^{\mathrm{m}-1}\left\{\beta_{\mathrm{h}}, \mathrm{b}_{\mathrm{h}}, \mathrm{h}=2, \ldots \mathrm{m}\right\}$

where $\mathrm{W}=\left\{\mathrm{W}_{1}, \ldots, \mathrm{W}_{\mathrm{m}}\right\}$, is a weighting vector, such that, $\mathrm{W}_{\mathrm{i}} \in[0,1]$ and $\Sigma_{\mathrm{i}} \mathrm{W}_{\mathrm{i}}=1 ; \beta_{\mathrm{h}}=\mathrm{W}_{\mathrm{h}} / \Sigma_{2}^{\mathrm{m}} \mathrm{W}_{\mathrm{k}}, \mathrm{h}=$ $2, \ldots \mathrm{m}$ andB is the associatedordered label vector. Each element $b_{i} \in B$ is the $i^{\text {th }}$ largest label in the collection $a_{1}$, . . . , $\mathrm{a}_{\mathrm{m}} \cdot \mathrm{C}^{\mathrm{m}}$ is the convex combination operator of $\mathrm{m}$ labels and if $\mathrm{m}=2$, then it is defined as

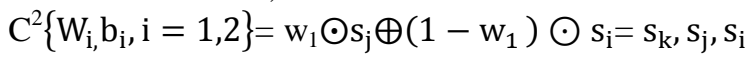

$\mathrm{S}(\mathrm{j} \geq \mathrm{i})$

such that $\mathrm{k}=\min \left\{\mathrm{T}, \mathrm{i}+\operatorname{round}\left(\mathrm{w}_{1} \cdot(\mathrm{j}-\mathrm{i})\right)\right\}$, where round is the usual round operation, and

$\mathrm{b}_{1}=\mathrm{s}_{\mathrm{j}}, \mathrm{b}_{2}=\mathrm{s}_{\mathrm{i}}$. If $\mathrm{w}_{\mathrm{j}}=1$ and $\mathrm{w}_{\mathrm{i}}=0$ with $\mathrm{i} \neq \mathrm{j}$, then the convex combination is defined as:

$\mathrm{C}^{\mathrm{m}}\left\{\mathrm{W}_{\mathrm{i}}, \mathrm{b}_{\mathrm{i}}, \mathrm{k}=1, \ldots, \mathrm{m}\right\}=\mathrm{b}_{\mathrm{j}}$.

$\mathrm{U}$, indicates the global preference between every ordered pair of alternatives according to the majority experts 'opinions. For example, a possibility to obtain $\mathrm{U}$ in the case of the linguistic interval fuzzy preference relations it would be as follows:

$\mathrm{U}=\left(\mathrm{U}_{\mathrm{ij}}\right)$ for $\mathrm{i}, \mathrm{j}=1, \ldots, \mathrm{n}$ with

$\mathrm{U}_{\mathrm{ij}}=\mathrm{U}\left[\mathrm{p}_{\mathrm{ij}}^{-}, \mathrm{p}_{\mathrm{ij}}^{+}\right]=\left[\phi_{-}\left(\mathrm{p}_{\mathrm{ij}}^{\mathrm{k}-}\right), \phi_{+}\left(\mathrm{p}_{\mathrm{ij}}^{\mathrm{k}+}\right)\right]$

$=\left[\min _{\mathrm{k}}\left(\mathrm{p}_{\mathrm{ij}}^{\mathrm{k}-}\right), \max _{\mathrm{k}}\left(\mathrm{p}_{\mathrm{ij}}^{\mathrm{k}+}\right)\right]$ for $\mathrm{k}=1, \ldots, \mathrm{n}$

With $\mathrm{w}_{-}=\{0, \ldots, 0,1\}$ in $\phi_{-}$and $\mathrm{w}_{+}=\{1,0, \ldots, 0\}$ in $\phi_{+}$

Obtain exploitation phase and select the more preferable value. Calculate its dominance degree $\mathrm{px}_{\mathrm{i}}$ from the collective linguistic interval fuzzy preference relation as:

$\mathrm{Px}_{\mathrm{i}}=\sum_{\substack{\mathrm{j}=1 \\ \mathrm{j} \neq \mathrm{i}}}^{\mathrm{n}}\left(\mathrm{s}\left(\mathrm{p}_{\mathrm{ij}}^{-}\right)+\mathrm{s}\left(\mathrm{p}_{\mathrm{ij}}^{+}\right)\right)$

In such a way, we obtain a classification of the alternatives: if $s\left(\mathrm{px}_{\mathrm{i}}\right)>\mathrm{s}\left(\mathrm{px}_{\mathrm{j}}\right)$ then $\mathrm{x}_{\mathrm{i}}$ is preferable to $\mathrm{x}_{\mathrm{j}}$ and therefore, the alternative $x_{i}$ is the recommended solution.

Step 5: Conduct consensus and proximity measures of the model. Consensus indicators are computed by the help of the following steps [11]:

Firstly, we compute the consensus relations of each expert $\mathrm{e}^{\mathrm{k}}$, called $\mathrm{C}^{\mathrm{k}}$, with respect to

$\mathrm{C}^{\mathrm{k}}=\left(\mathrm{C}_{\mathrm{ij}}^{\mathrm{k}}\right)$ with

For $i, j=1, \ldots, n$
Secondly, we define the linguistic global consensus degree, LCD, as,

$$
\begin{aligned}
\sum_{i=1}^{n} \operatorname{LCD}_{i} & =1-\sum_{i=1}^{n} \sum_{\substack{j=1 \\
j \neq i}}^{n} \sum_{k=1}^{m} C_{i j}^{k} /\left(\left(n^{2}-n\right) m\right) \\
& =\text { CD. }
\end{aligned}
$$

Now, we continue with the process in order to calculate the proximity measures. Firstly, we calculate the expert proximity relations, called $\mathrm{F}_{\mathrm{k}}$, with respect to the collective preference relation $\mathrm{U}$ as:

$\mathrm{F}^{\mathrm{k}}=\mathrm{F}_{\mathrm{ij}}^{\mathrm{k}}$ with

$$
\begin{aligned}
\mathrm{F}_{\mathrm{ij}}^{\mathrm{k}} & =\left(\mathrm{s}\left(\mathrm{p}_{\mathrm{ij}}^{\mathrm{k}-}\right)-\mathrm{s}\left(\mathrm{p}_{\mathrm{ij}}\right), \mathrm{s}\left(\mathrm{p}_{\mathrm{ij}}^{\mathrm{k}+}\right)-\mathrm{s}\left(\mathrm{p}_{\mathrm{ij}}\right)\right) \\
& =\left(\mathrm{f}_{\mathrm{ij}}^{\mathrm{k}-}, \mathrm{f}_{\mathrm{ij}}^{\mathrm{k}+}\right)
\end{aligned}
$$

For $\mathrm{i}, \mathrm{j}=1, \ldots, \mathrm{n}$ and $\mathrm{p}_{\mathrm{ij}}=\phi_{\mathrm{Q}}\left(\mathrm{p}_{\mathrm{ij}}^{-}, \mathrm{p}_{\mathrm{ij}}^{+}\right)$and $s\left(\mathrm{p}_{\mathrm{ij}}\right)=\mathrm{n}$ If $\mathrm{p}_{\mathrm{ij}}=\mathrm{s}_{\mathrm{n}}$.

Then, we define the proximity measure of the expert $e^{k}$ on a preference $\mathrm{p}_{\mathrm{ij}}$ as:

$\mathrm{PM}_{\mathrm{ij}}^{\mathrm{k}}=\left(\left|\mathrm{f}_{\mathrm{ij}}^{\mathrm{k}-}\right|+\left|\mathrm{f}_{\mathrm{ij}}^{\mathrm{k}+}\right|\right) / 2 \mathrm{~T}$

After that, we should define the proximity measure of the expert $\mathrm{e}^{\mathrm{k}}$ in an alternative $\mathrm{x}_{\mathrm{i}}$ as

$$
\mathrm{PM}_{\mathrm{i}}^{\mathrm{k}}=\sum_{\substack{\mathrm{j}=1 \\ \mathrm{j} \neq \mathrm{i}}}^{\mathrm{n}} \mathrm{PM}_{\mathrm{ij}}^{\mathrm{k}} /(\mathrm{n}-1)
$$

Then, we have to define the global proximity measure of the expert $\mathrm{e}^{\mathrm{k}}$ as:

$$
\mathrm{PM}^{\mathrm{k}}=\sum_{\mathrm{i}=1}^{\mathrm{n}} \mathrm{PM}_{\mathrm{i}}^{\mathrm{k}} /(\mathrm{n})
$$

Step 6: Checking consistencies and doing the feedback process. The feedback mechanism helps to guide the change of the expert's opinions using with proximity matrices $F^{k}$ [26],[41-43].To reach a consensus, this mechanism provides a good control of consistencies and if there are inconsistencies, then the expert's preferences should be revised.

Feedback mechanism is accomplished in two phases:

- Identification phase,

- Recommendation phase.

Identification phase: It is necessary to compare the global consensus degree LCD and a consensus threshold A, previously fixed. Then, if LCD > A or $\mathrm{LCD}=\mathrm{A}$ the consensus process will stop; on the other hand, if $\mathrm{LCD}<\mathrm{A}$, a new consensus round must be applied. Firstly, the pairs of alternatives with a consensus degree smaller than a threshold value $\mathrm{A}$ defined at level of pairs of alternatives, $\mathrm{CD}_{\mathrm{ij}}<\mathrm{A}$, are identified. Secondly, we identify the experts who will be required to modify the identified pairs of alternatives. To do that, we use the expert proximity measures $\mathrm{PM}^{\mathrm{k}}$ and $\mathrm{PM}_{\mathrm{i}}^{\mathrm{k}}$, and also we fix a value threshold $\mathrm{B}$. The experts that are required to be modified are preferences whose $\mathrm{PM}^{\mathrm{k}}>\mathrm{B}$.

Recommendation phase: In this phase we recommend expert changes of their preferences according to some rules to change the opinions.

Step 7: Form the supermatrix of ANP model. A supermatrix is a partitioned matrix, where each 
submatrice is composed of a set of relationships between two clusters. After establishing the supermatrix, we normalize it so that the numbers in every column add up to one. To derive the overall priorities of elements, we need to multiply the submatrices until the columns stabilize and become identical in each block of submatrices. It is necessary to raise the unweighted supermatrix to the power of $2 n+1$ where $\mathrm{n}$ is an arbitrary large number. Raising a matrix to powers gives the long term relative influences of the elements on each other, and this new matrix is called the limit supermatrix [12].

Step 8: Determine the most appropriate alternative.

\section{An illustrative example: Partner selection for customized product development}

To illustrate our approach, we give an illustrative example on the partner selection problem for customized product development.

Step 1: There are three DMs and four possible partner alternatives (P1, P2, P3, P4).The evaluation system consists of three main dimensions: Customization Strategies, Performance and Partner Evaluation Criteria. The evaluation network structure, interactions and interdependency relationships of evaluation elements are depicted in Figure 2.

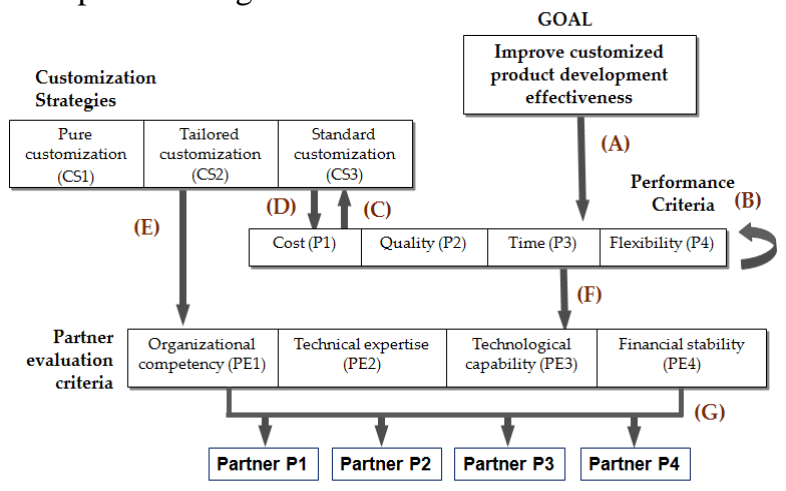

Figure 2.Network model of evaluation structure.

The notation for supermatrix is in Table 3 where relations forcomparisons are presented with letters and I is the identity matrix.

\begin{tabular}{lccccc}
\hline & Goal & PC & CS & PEC & ALTS \\
\hline Goal & 0 & 0 & 0 & 0 & 0 \\
Performance criteria (PC) & A & B & D & 0 & 0 \\
Customization strategies(CS) & 0 & C & 0 & 0 & 0 \\
Partner evaluation c. (PEC) & 0 & F & E & 0 & 0 \\
ALTS & 0 & 0 & 0 & G & I \\
\hline
\end{tabular}

Table 3. General submatrix notation for supermatrix.

Step 2: The linguistic evaluation scale has already been discussed in Section 3.

Step 3: The importance degrees of criteria and alternatives are considered and DMs' preferences using linguistic interval fuzzy preference relations are given in Tables 4, 5, 6 respectively.

\begin{tabular}{lcclc}
\hline Assessment & $(\mathrm{P} 1)$ & $(\mathrm{P} 2)$ & $(\mathrm{P} 3)$ & $(\mathrm{P} 4)$ \\
\hline Cost $(\mathrm{P} 1)$ & - & {$[\mathrm{VLC}, \mathrm{MC}]$} & {$[\mathrm{SC}, \mathrm{ML}]$} & {$[\mathrm{SC}, \mathrm{ML}]$} \\
Quality (P2) & {$[\mathrm{VLC}, \mathrm{IM}]$} & - & {$[\mathrm{SC}, \mathrm{MC}]$} & {$[\mathrm{VLC}, \mathrm{ML}]$} \\
Time (P3) & {$[\mathrm{MC}, \mathrm{EL}]$} & {$[\mathrm{MC}, \mathrm{C}]$} & - & {$[\mathrm{SC}, \mathrm{EL}]$} \\
Flexibility(P4) & {$[\mathrm{EU}, \mathrm{SC}]$} & {$[\mathrm{VLC}, \mathrm{ML}]$} & {$[\mathrm{SC}, \mathrm{MC}]$} & - \\
\hline
\end{tabular}

Table 4. First DM's evaluation of performance criteria

\begin{tabular}{ccccc}
\hline Assessment & $(\mathrm{P} 1)$ & $(\mathrm{P} 2)$ & $(\mathrm{P} 3)$ & $(\mathrm{P} 4)$ \\
\hline$(\mathrm{P} 1)$ & - & {$[\mathrm{VLC}, \mathrm{MC}]$} & {$[\mathrm{SC}, \mathrm{ML}]$} & {$[\mathrm{EU}, \mathrm{SC}]$} \\
$(\mathrm{P} 2)$ & {$[\mathrm{VLC}, \mathrm{IM}]$} & - & {$[\mathrm{SC}, \mathrm{EL}]$} & {$[\mathrm{EU}, \mathrm{IM}]$} \\
$(\mathrm{P} 3)$ & {$[\mathrm{VLC}, \mathrm{MC}]$} & {$[\mathrm{SC}, \mathrm{EL}]$} & - & {$[\mathrm{SC}, \mathrm{ML}]$} \\
$(\mathrm{P} 4)$ & {$[\mathrm{VLC}, \mathrm{MC}]$} & {$[\mathrm{VLC}, \mathrm{ML}]$} & {$[\mathrm{VLC}, \mathrm{IM}]$} & - \\
\hline
\end{tabular}

Table 5. Second DM's evaluation of performance criteria

\begin{tabular}{ccccc}
\hline Assessment & $(\mathrm{P} 1)$ & $(\mathrm{P} 2)$ & $(\mathrm{P} 3)$ & $(\mathrm{P} 4)$ \\
\hline$(\mathrm{P} 1)$ & - & {$[\mathrm{SC}, \mathrm{IM}]$} & {$[\mathrm{IM}, \mathrm{EL}]$} & {$[\mathrm{MC}, \mathrm{C}]$} \\
$(\mathrm{P} 2)$ & {$[\mathrm{VLC}, \mathrm{SC}]$} & - & {$[\mathrm{MC}, \mathrm{C}]$} & {$[\mathrm{IM}, \mathrm{ML}]$} \\
$(\mathrm{P} 3)$ & {$[\mathrm{SC}, \mathrm{MC}]$,} & {$[\mathrm{SC}, \mathrm{EL}]$} & - & {$[\mathrm{IM}, \mathrm{MC}]$} \\
$(\mathrm{P} 4)$ & {$[\mathrm{VLC}, \mathrm{IM}]$} & {$[\mathrm{SC}, \mathrm{ML}]$} & {$[\mathrm{EU}, \mathrm{SC}]$} & - \\
\hline
\end{tabular}

Table 6. Third DM's evaluation of performance criteria

Step 4: Aggregation of collective linguistic interval fuzzy preference relations.

Using the previous aggregation tool and Eq. (1)-(4) we obtain $\mathrm{U}$ as shown in Table 7.

\begin{tabular}{ccccc}
\hline $\mathrm{U}$ & $(\mathrm{P} 1)$ & $(\mathrm{P} 2)$ & $(\mathrm{P} 3)$ & $(\mathrm{P} 4)$ \\
\hline$(\mathrm{P} 1)$ & - & {$[\mathrm{SC}, \mathrm{IM}]$} & {$[\mathrm{IM}, \mathrm{EL}]$} & {$[\mathrm{Ml}, \mathrm{C}]$} \\
$(\mathrm{P} 2)$ & {$[\mathrm{SC}, \mathrm{MC}]$} & - & {$[\mathrm{MC}, \mathrm{ML}]$} & {$[\mathrm{SC}, \mathrm{IM}]$} \\
$(\mathrm{P} 3)$ & {$[\mathrm{SC}, \mathrm{IM}]$} & {$[\mathrm{IM}, \mathrm{ML}]$} & - & {$[\mathrm{IM}, \mathrm{MC}]$} \\
$(\mathrm{P} 4)$ & {$[\mathrm{VLC}, \mathrm{IM}]$} & {$[\mathrm{EU}, \mathrm{IM}]$} & {$[\mathrm{EU}, \mathrm{SC}]$} & - \\
\hline
\end{tabular}

Table 7. Collective linguistic interval fuzzy preference relation of performance criteria

Step 5: Conduct consensus and proximity measures of the model: Consensus relations using Eq. (5-6) is calculated and first DMs consensus matrices are as follows:

$$
C^{1}=\left(\begin{array}{cccc}
- & 1 / 4 & 1 / 4 & 5 / 8 \\
1 / 4 & - & 3 / 8 & 3 / 8 \\
5 / 8 & 3 / 8 & - & 3 / 8 \\
1 / 4 & 3 / 8 & 1 / 2 & -
\end{array}\right)
$$

From calculation using Equation (17), global consensus degree (CD) is obtained as 0.697 (or $C D=69.7 \%$ ). Then we fix a consensus threshold value $\mathrm{A}$ is equal to 0.7 . This means that if CD is less than 0.7; it seems not to be acceptable and the DMs should perform the pair wise comparison again. However, to be able to sure that DM's judgment is acceptable, we have to measure the DM proximity relations called $\mathrm{F}^{\mathrm{k}}$ with the help of Eq. (7).As an example the $\mathrm{F}^{\mathrm{k}}$ for first $\mathrm{DM} \mathrm{e}^{1}$ is:

$$
\mathrm{F}^{1}=\left(\begin{array}{cccc}
- & (-2,1) & (-3,0) & (-4,-1) \\
(-2,0) & - & (-3,-1) & (-2,2) \\
(1,3) & (0,3) & - & (-2,2) \\
(-2,0) & (-1,3) & (1,3) & -
\end{array}\right)
$$

The proximity measures for DMs $\mathrm{e}^{\mathrm{k}}$ in each alternative $\mathrm{X}_{\mathrm{i}}$ are calculated using Eq. (8)-(11), and the results are: $\mathrm{PM}_{1}^{1}=0.229 \mathrm{PM}_{1}^{2}=0.333 \quad \mathrm{PM}_{1}^{3}=0.146$

$\mathrm{PM}_{1}^{2}=0.208 \quad \mathrm{PM}_{2}^{2}=0.188 \quad \mathrm{PM}_{2}^{3}=0.167$

$\mathrm{PM}_{1}^{3}=0.229 \mathrm{PM}_{3}^{2}=0.208 \quad \mathrm{PM}_{3}^{3}=0.146$

$\mathrm{PM}_{1}^{4}=0.208 \mathrm{PM}_{4}^{2}=0.208 \quad \mathrm{PM}_{4}^{3}=0.146$

And,

$$
\mathrm{PM}^{1}=0.219 ; \mathrm{PM}^{2}=0.234 ; \mathrm{PM}^{3}=0.151 .
$$


Step 6: Checking consistencies and do feedback process. DMs should change their preferences in order to achieve appropriate agreement degree. If we fix a threshold value to 0.15 , those DMs should change their assessments, especially DM1 and DM2.So, DMs focus on new assessments which are given in Tables 8, 9 and 10 respectively.

\begin{tabular}{lcccc}
\hline Assessment & $(\mathrm{P} 1)$ & $(\mathrm{P} 2)$ & $(\mathrm{P} 3)$ & $(\mathrm{P} 4)$ \\
\hline (P1) & - & {$[\mathrm{IM}, \mathrm{EL}]$} & {$[\mathrm{MC}, \mathrm{EL}]$} & {$[\mathrm{ML}, \mathrm{C}]$} \\
(P2) & {$[\mathrm{SC}, \mathrm{MC}]$} & - & {$[\mathrm{SC}, \mathrm{ML}]$} & {$[\mathrm{VLC}, \mathrm{IM}]$} \\
(P3) & {$[\mathrm{VLC}, \mathrm{IM}]$} & {$[\mathrm{SC}, \mathrm{MC}]$} & - & {$[\mathrm{IM}, \mathrm{MC}]$} \\
(P4) & {$[\mathrm{I}, \mathrm{EU}]$} & {$[\mathrm{EU}, \mathrm{SC}]$} & {$[\mathrm{EU}, \mathrm{SC}]$} & - \\
\hline
\end{tabular}

Table 8.First DM's renewed evaluation of pref.criteria

\begin{tabular}{lcccc}
\hline Assessment & $(\mathrm{P} 1)$ & $(\mathrm{P} 2)$ & $(\mathrm{P} 3)$ & $(\mathrm{P} 4)$ \\
\hline (P1) & - & {$[\mathrm{MC}, \mathrm{C}]$} & {$[\mathrm{ML}, \mathrm{C}]$} & {$[\mathrm{EL}, \mathrm{C}]$} \\
$(\mathrm{P} 2)$ & {$[\mathrm{IM}, \mathrm{ML}]$} & - & {$[\mathrm{IM}, \mathrm{EL}]$} & {$[\mathrm{VLC}, \mathrm{MC}]$} \\
$(\mathrm{P} 3)$ & {$[\mathrm{SC}, \mathrm{MC}]$} & {$[\mathrm{IM}, \mathrm{ML}]$} & - & {$[\mathrm{IM}, \mathrm{ML}]$} \\
(P4) & {$[\mathrm{I}, \mathrm{VLC}]$} & {$[\mathrm{EU}, \mathrm{IM}]$} & {$[\mathrm{VLC}, \mathrm{IM}]$} & - \\
\hline
\end{tabular}

Table 9. Second DM's renewed evaluation of pref. criteria

\begin{tabular}{lcccc}
\hline Assessment & (P1) & (P2) & (P3) & (P4) \\
\hline (P1) & - & {$[\mathrm{MC}, \mathrm{EL}]$} & {$[\mathrm{ML}, \mathrm{EL}]$} & {$[\mathrm{ML}, \mathrm{C}]$} \\
(P2) & {$[\mathrm{IM}, \mathrm{MC}]$} & - & {$[\mathrm{SC}, \mathrm{EL}]$} & {$[\mathrm{VLC}, \mathrm{IM}]$} \\
(P3) & {$[\mathrm{SC}, \mathrm{IM}]$,} & {$[\mathrm{SC}, \mathrm{ML}]$} & - & {$[\mathrm{IM}, \mathrm{MC}]$} \\
(P4) & {$[\mathrm{I}, \mathrm{VLC}]$} & {$[\mathrm{EU}, \mathrm{SC}]$} & {$[\mathrm{VLC}, \mathrm{SC}]$} & - \\
\hline
\end{tabular}

Table 10. Third DM's renewed evaluation of pref. criteria

Then, we obtain the following collective linguistic interval fuzzy preference relation $U$ as given in Table 11 .

\begin{tabular}{ccccc}
\hline $\mathrm{U}$ & $(\mathrm{P} 1)$ & $(\mathrm{P} 2)$ & $(\mathrm{P} 3)$ & $(\mathrm{P} 4)$ \\
\hline (P1) & - & {$[\mathrm{MC}, \mathrm{EL}]$} & {$[\mathrm{ML}, \mathrm{EL}]$} & {$[\mathrm{EL}, \mathrm{C}]$} \\
$(\mathrm{P} 2)$ & {$[\mathrm{IM}, \mathrm{MC}]$} & - & {$[\mathrm{IM}, \mathrm{ML}]$} & {$[\mathrm{VLC}, \mathrm{IM}]$} \\
$(\mathrm{P} 3)$ & {$[\mathrm{SC}, \mathrm{IM}]$} & {$[\mathrm{IM}, \mathrm{MC}]$} & - & {$[\mathrm{IM}, \mathrm{MC}]$} \\
(P4) & {$[\mathrm{I}, \mathrm{EU}]$} & {$[\mathrm{EU}, \mathrm{SC}]$} & {$[\mathrm{VLC}, \mathrm{SC}]$} & - \\
\hline
\end{tabular}

Table 11. Collective linguistic interval fuzzy preference relation of performance criteria

In this case, global consensus degree is $C D=0.91319$ and the threshold ratio is less than $\mathrm{CD}$ which means acceptable. Finally, collective fuzzy preference relations matrix $(\mathrm{U})$ is suitable to indicate dominance degrees of each weight which is: $\mathrm{px}_{1}=0.40 ; \mathrm{px}_{2}=0.25$; $\mathrm{px}_{3}=0.25 ; \mathrm{px}_{4}=0.10$.

Step 7: Form supermatrix: An unweighted supermatrix is formed by including priority vectors in the related columns.

Step 8: Determine the suitable partner alternative. Afterwards by normalizing the unweighted supermatrix and raising it to the power of 5 , the weighted supermatrix is attained. The final ranking is given in Table 12. The obtained result shows that Alternative $\mathrm{C}$ has the highest score among all alternatives and it can be identified as the most suitable partner for improving the customized product development effectiveness.

\begin{tabular}{cc}
\hline Alternative & Weight \\
\hline A & 0.265 \\
B & 0.226 \\
C & 0.274 \\
D & 0.235 \\
\hline
\end{tabular}

Table 12. Final ranking in customized product development partner selection problem

\section{Concluding remarks}

In some evaluation and decision situations, DMs have difficulty to express some preferences by means of exact preference degrees. In order to represent their preferences accurately, this study supported an approach that enables a combined consensus model in GDM with linguistic interval fuzzy preference relations. In addition, for dealing with the dependency of evaluation criteria, ANP is capable of incorporating many interrelationships of factors into the decision model. For this reason, an integrated methodology based on fuzzy ANP and incomplete preference relations was proposed in this study. An illustrative customized product development partner evaluation case was used to exemplify the proposed framework. To our knowledge, no previous work has investigated this new integrated approach. As the proposed approach is new and applied to partner selection process as an illustrative example, it might be applied to other GDM problems and can be used for real life applications.

\section{References}

[1] C.L. Hwang, M.J. Lin, Group Decision-Making under Multiple Criteria: Methods and Applications, SpringerVerlag, Berlin, 1987.

[2] G. Büyüközkan, O. Feyzioglu, D. Ruan, Fuzzy group decision-making approach to multiple preference formats in quality function deployment, Computers in Industry, 58 (5), 392-402, 2007.

[3] O. Feyzioglu, G. Büyüközkan, An integrated group decision-making approach for new product development, International Journal of Computer Integrated Manufacturing, 21, 366-375, 2008.

[4] R.M. Rodriguez, L. Martinez, F. Herrera, A group decision making model dealing with comparative linguistic expressions based on hesitant fuzzy linguistic term sets, Information Sciences, 241,28-42,2013.

[5]F. Herrera, A sequential selection process in group decision making with linguistic assessment, Information Sciences 85, 223-239, 1995.

[6]F. Herrera, E. Herrera-Viedma, J.L. Verdegay, A rational consensus model in group decision making using linguistic assessments, Fuzzy Sets and Systems, 88(1), 31-49, 1997.

[7]F. Herrera, E. Herrera-Viedma, Linguistic decision analysis: steps for solving decision problems under linguistic information, Fuzzy Sets and Systems 115 (1), 67-82, 2000.

[8] Z.S. Xu, A method based on linguistic aggregation operators for group decision making with linguistic preference relations, Information Sciences 166, 19-30, 2004.

[9] L. Zhou, H. Chen, A generalization of the power aggregation operators for linguistic environment and its application in group decision making, Knowledge-Based Systems 26, 216-224, 2012.

[10] D. Meng, Z. Pei, On weighted unbalanced linguistic aggregation operators in group decision making, Information Sciences, 223, 31-41, 2013.

[11] J. M. Tapia Garcia, M.J. del Moral, M.A. Martinez, E. Herrera-Viedma, A consensus model for group decision making problems with linguistic interval fuzzy preference relations, Expert Systems with Applications 39, 10022-10030, 2012.

[12] T.L. Saaty, Decision Making with Dependence and Feedback: The Analytic Network Process, RWS Publications, Pittsburgh, 1996. 
[13] G. Büyüközkan, G. Çifçi, A novel fuzzy multi-criteria decision framework for sustainable supplier selection with incomplete information, Computers in Industry 62, 164-174, 2011

[14] E. Herrera-Viedma, F. Chiclana, F. Herrera, S. Alonso, A consensus model for group decision making with incomplete fuzzy preference relations, IEEE Transactions On Fuzzy Systems, 15(5), 863-877, 2007.

[15] G. H, Marakas, Decision Support Systems in the 21th Century, 2nd ed., Pearson Education, Upple Saddle River, NJ, 2003.

[16] J.M. Moreno-Rodriguez, F.J. Cabrerizo,I.J. Perez, M.A. Martinez, A consensus support model based on linguistic information fort he initial self assesment of EFQM in health care organizations, 40, 2792-2798, 2013.

[17] C. Von Altrock, Fuzzy logic and neurofuzzy applications in business and finance. New Jersey: Prentice-Hall, 1996.

[18] L.A. Zadeh, Fuzzy set, Information and Control 8, 338353, 1965.

[19] L. A. Zadeh, The concept of a linguistic variable and its applications to approximate reasoning. Part I., Information Sciences, 8, 199-249, 1975.

[20] J. Lan, Q. Sun, Q. Chen, Z. Wang, Group decision making based on induced uncertain linguistic OWA operators, Decision Support Systems, In Press, Available at www.sciencedirect.com

[21] R.R. Yager, On ordered weighted averaging aggregation operators in multicriteria decision making, IEEE Transactions on Systems, Man, and Cybernetics 18, 183-190, 1988.

[22] F. Herrera, L.Martínez, A 2-tuple fuzzy linguistic representationmodel for computing with words, IEEE Transactions on Fuzzy Systems 8, 746-752, 2000.

[23] Z.S. Xu, A practical method for priority of interval number complementary judgment matrix, Operations Research and Management Science 10,16-19, 2001.

[24] Z.S. Xu, On compatibility of interval fuzzy preference matrices, Fuzzy Optimization and Decision Making 3, 217225, 2004.

[25] F. Herrera, L. Martinez, P.J. Sanchez, Managing nonhomogeneous information in group decision making, European Journal of Operational Research 166, 115-132, 2005.

[26] E. Herrera-Viedma, F. Chiclana, F. Herrera, S. Alonso, Group decision-making model with incomplete fuzzy preference relations based on additive consistency, IEEE Transactions on Systems, Man and Cybernetics-Part B: Cybernetics, 37(1), 176-189, 2007.

[27] S.-C. Chen, S.-M. Chen, A new information fusion method based on interval-valued fuzzy numbers for handling multi criteria decision making problems, FUZZ-IEE, Budapest Hungary, 25-29 July, 2004.

[28] J.Q. Wang, XH. Chen, Multi-criteria linguistic interval group decision-making approach, Journal of System Engineering, 19(5), 934 - 938, 2008.

[29] S. Genc, F.E. Boran, D. Akay, Z. Xu, Interval multiplicative transitivity for consistency, missing values and priority weights of interval fuzzy preference relations, Information Sciences 180,4877- 4891, 2012.
[30] Z.S. Xu, J. Chen, Some models for deriving the priority weights from interval fuzzy preference relations, European Journal of Operational Research 184, 266-280, 2008.

[31] P. Liu, F. Jin, X. Zhang, Y. Su, M. Wang, Research on the multi-attribute decision-making under risk with interval probability based on prospect theory and the uncertain linguistic variables, Knowledge Based Systems, 24, 554- 561, 2011.

[32] Z.S. Xu, Consistency of interval fuzzy preference relations in group decision making, Applied Soft Computing, $11,3898-3909,2011$

[33] S.-M. Chen, L.W.Lee, S.-W.Yang, T.-W.Sheu, Adaptive consensus support model for group decision making systems,ExpertSytems with Applications, 39, 12580-12588, 2012.

[34] P. Liu, Some geometric aggregation operators based on interval intuitionistic encertaion linguistic variables and their application to group decision making, Applied Mathematical Modeling, 37, 2430-2444, 2013.

[35] H. Zhang, Some interval-valued 2-tuple linguistic aggregation operators and application in multi attribute group decision making, Applied Mathematical Modelling, 37, 42694282, 2013.

[36] T. Paksoy, N.Y.Pehlivan, Fuzzy linear programming model for the optimization of multi-stage supply chain networks with triangular and trapezoidal membership functions, Journal of the Franklin Institute, 349, 93-109, 2012.

[37] F. Herrera, E. Herrera-Viedma, Choice functions and mechanisms for linguistic preference relations, European Journal of Operational Research, 120(1), 144-161, 2000.

[38] E. Herrera-Viedma, E. Peis, Evaluating the informative quality of documents in SGML format from judgements by means of fuzzy linguistic techniques based on computing with words, Information Processing \& Management, 39(2), 233249, 2003.

[39] F. Herrera, E. Herrera-Viedma, J. L Vergeday, Linguistic measures based on coincidence for reaching consensus in group decision making, International Journal of Approximate Reasoning 16(3-4), 309-334, 1997.

[40] F. Herrera,E. Herrera-Viedma, Aggregation operators for linguistic weighted information, IEEE Transactions on Systems, Man and Cybernetics-Part A: Systems and Humans, 27(5), 1997.

[41] E. Herrera-Viedma, F. Herrera, \& F. Chiclana, A consensus model for multiperson decision making with different preference structures, IEEE Transactions on Systems, Man and Cybernetics-Part A: Systems and Humans, 32(3), 394-402, 2002.

[42] F. Mata, L. Martínez, \& E. Herrera-Viedma, An adaptive consensus support model for group decision making problems in a multi-granular fuzzy linguistic context. IEEE Transactions on fuzzy Systems, 17(2), 279-290, 2009.

[43] E. Herrera-Viedma, L. Martínez, F. Mata, F. Chiclana , A consensus support system model for group decision-making problems with multi-granular linguistic preference relations, IEEE Transactions on Fuzzy Systems, 13, 644-645, 2005 